\title{
Effect of changing painting parameters on surface gloss and roughness
}

\section{Original Article}

\author{
Ahmed Samy Elakkad, Ramadan Badawy Elgamasy \\ Department of Design and Production Engineering, Ain Shams University, Cairo, \\ Egypt
}

\section{Keywords:}

Rough surface, painting, specular reflectancet

\section{Corresponding Author:}

Ahmed Samy Elakkad, Department of Design and Production Engineering, Ain Shams University, Cairo, Egypt, Tel: 00201000735559.

Email: tawfeik2015@gmail.com

\section{Abstract}

Surface topography (as Roughness) and gloss of the thermoplastic are affected by varying in painting parameters greatly. Gloss of thermoplastic reflects light through the surface in a specular direction, it is a quality factor in the visual test of final products. Surface roughness of a thermoplastic had a role in determination of optical behaviour and aesthetic appearance. The experiments presented in this paper shows the effect of painting parameters changing on gloss and surface topography of thermoplastic parts. Eight painting parameters were chosen to study their effect. Gloss and roughness measured for the molded samples which molded in a mold-cavity with a rectangular impression in Arburg all-rounder 320C- 600250/molding machine (figure 1) that mounted at conveyor of an automated spray-painting machine. And then the parameters of painting (material pressure, gun height, oven drying temperature time, and gun angle) were changed each trial to see its effect.

\section{INTRODUCTION}

Gloss is an optical property that indicates how far the surface of the light is reflected in a bright direction. Factors affecting luminance are the refractive index of the material, the angle of incident light and the surface roughness. Analytical expressions are derived for gloss and other semi-exponential functions. The inconsistency in gloss was found to be important in common polymer surfaces. The latter means that surface height links cannot be neglected in the luminance assessment ${ }^{[1]}$.

Surface roughness and incident angle affect in reflectanceof low gloss coatings with grazing incidence $^{[2]}$. The experimental study discuss the relations between the contrast of surface coating and gloss, roughness of surface ${ }^{[3]}$. In order to achieve the glossy finish surfaces, it is necessary to polish surfaces coated with high gloss. Rub means sanding the final surfaces with a fine abrasive scrub. The results showed that during polishing, the roughness of the surface decreased, while the final surface gloss increased ${ }^{[4]}$.

When evaluating the metal surface texture, the evaluation parameters used for surface texture were roughness, glossing and color using the CIELAB method (the ICRC laboratory for the design plant). The results indicated that the lower the roughness of the surface, the greater the value of gloss. The illumination value of the CIELAB color space decreased, as the roughness of the surface decreased. Therefore, the relationship between the value of lightness and the value of surface roughness showed an inverse relationship with the value of gloss and the roughness of the surface, where the blue color increased as the surface roughness of several types of materials ${ }^{[5]}$.

In the present paper, the effect of surface finishes on varieties of ornamentalgranite that used in building construction, was analyzed by means of roughness, color,and gloss measurements to provide an objective standardizedmethod of aesthetic characterization useful for the different workersin the fields of construction and building materials ${ }^{[6]}$.

The studying began with explaining why we chose to study perceived gloss, then describe the samples manufacturing process, and finally the model parameters that comprise the space to be investigated ${ }^{[7]}$.

\section{Relations between Surface Gloss and Surface Roughness}

Surface roughness ${ }^{[8]}$ is the shortest frequency of real surfaces relative to basins. Roughness has a good predictor of mechanical component performance, because irregularities on the surface may form the nucleus of cracking or corrosion. Mean roughness, root means square roughness, roughness depth, personal tendency roughness and root slope root mean is the mean roughness measurement parameters.

Surface gloss $^{[9]}$ is the characteristic of surfaces that have a glossy, matte or glossy appearance. It is an optical property that indicates the extent of its reflection 


\section{Experimental Work:}

The samples that used in the presented work were made from pure polyamide (PA), 15\% glass reinforced polyamide, $30 \%$ glass reinforced polyamide and $50 \%$ glass reinforced poly amide were used. It produced from injecting polyamide in a mold-cavity with a rectangular impression in Arburg All-rounder 320 C-600/250 molding machine (Figure1). After injection molding the test plates, they were supported on the conveyor of an automated Venjakob machine (spray painting machine) to be painted. The painting process repeated several times with changing in a painting parameter such, Material pressure, gun height, wide pressure, oven drying temperature time, and gun angle. After painting the samples gloss measured with glossmeter (Zehntner 1120), and roughness measured by (The Taylor-Hobson Surtonic 3 Roughness Gage).

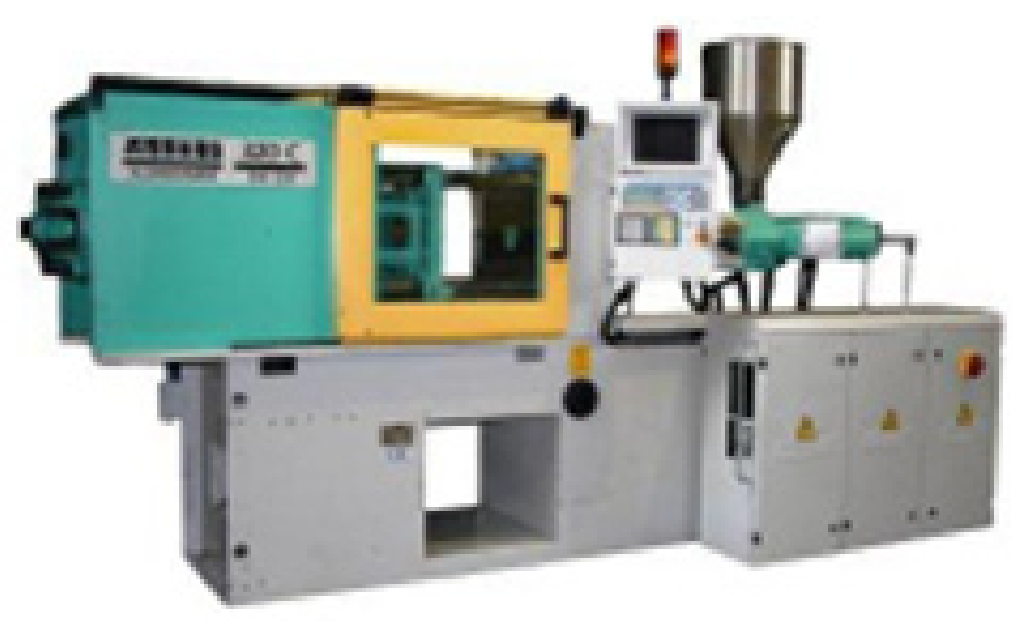

Fig. 1: Arburg all-rounder 320C-600/250 molding machine

\section{Results and Discussion:}

In injection molding many parameters need to be controlled, temperature, pressure, time. but in the presented work a focus on the major parameters that has the greatest effect on the melt and the part will be formed. Change in surface roughness and surface gloss related to changing in Material pressure, gun height, wide pressure, oven drying temperature time, and gun angle for the four types of samples (PA, $15 \%$ glass reinforced polyamide, $30 \%$ glass reinforced polyamide, $50 \%$ glass reinforced polyamide) discussed as the following figures shown.

IV.1. Material Pressure

IV.1.1. Surface Roughness

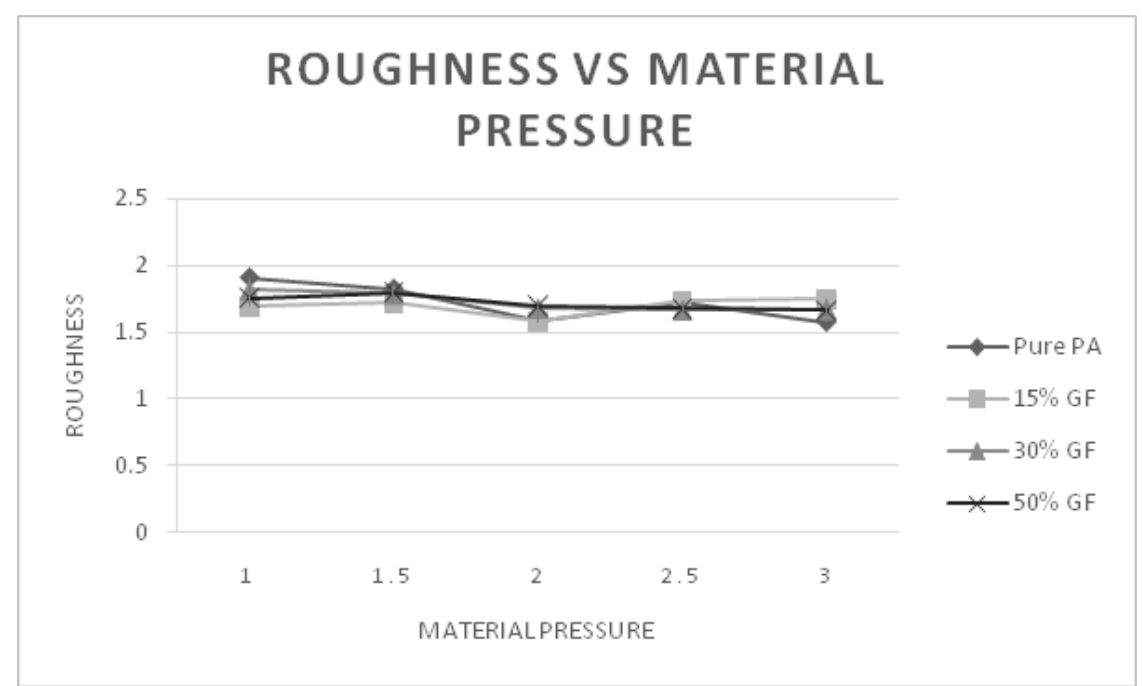

Fig. 2: Change in surface roughness $(\mu \mathrm{m})$ with changing in material pressure (MPa) 
IV.1.2. Surface Gloss

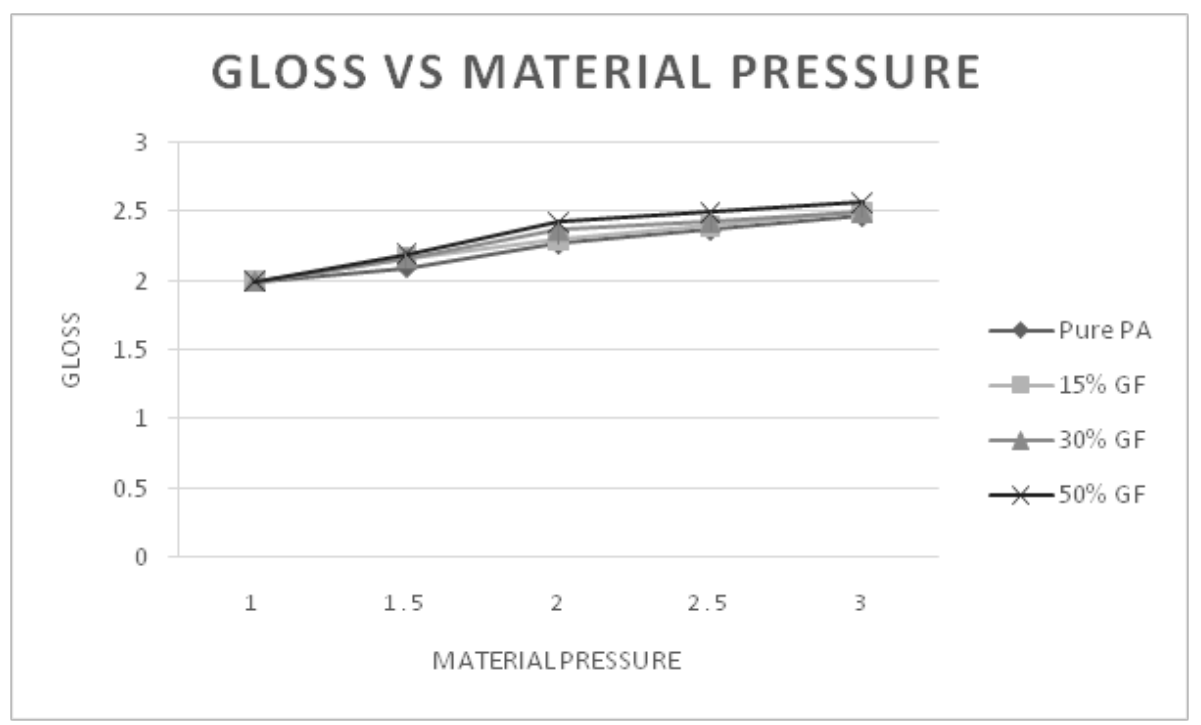

Fig. 3: Change in surface gloss $(\mathrm{Gu})$ with changing in material pressure (MPa)

Gloss readings of all samples (pure PA, 15\%GF, $30 \% \mathrm{GF}$, and $50 \% \mathrm{GF}$ ) increased while roughness readings decreased with the increase of material pressure and that's because of the increase of flow rate and so more material was painted which reduced the roughness of substrate and as a result the gloss increased.

IV.2. Effect of Changing Gun Height

IV.2.1. Surface Roughness

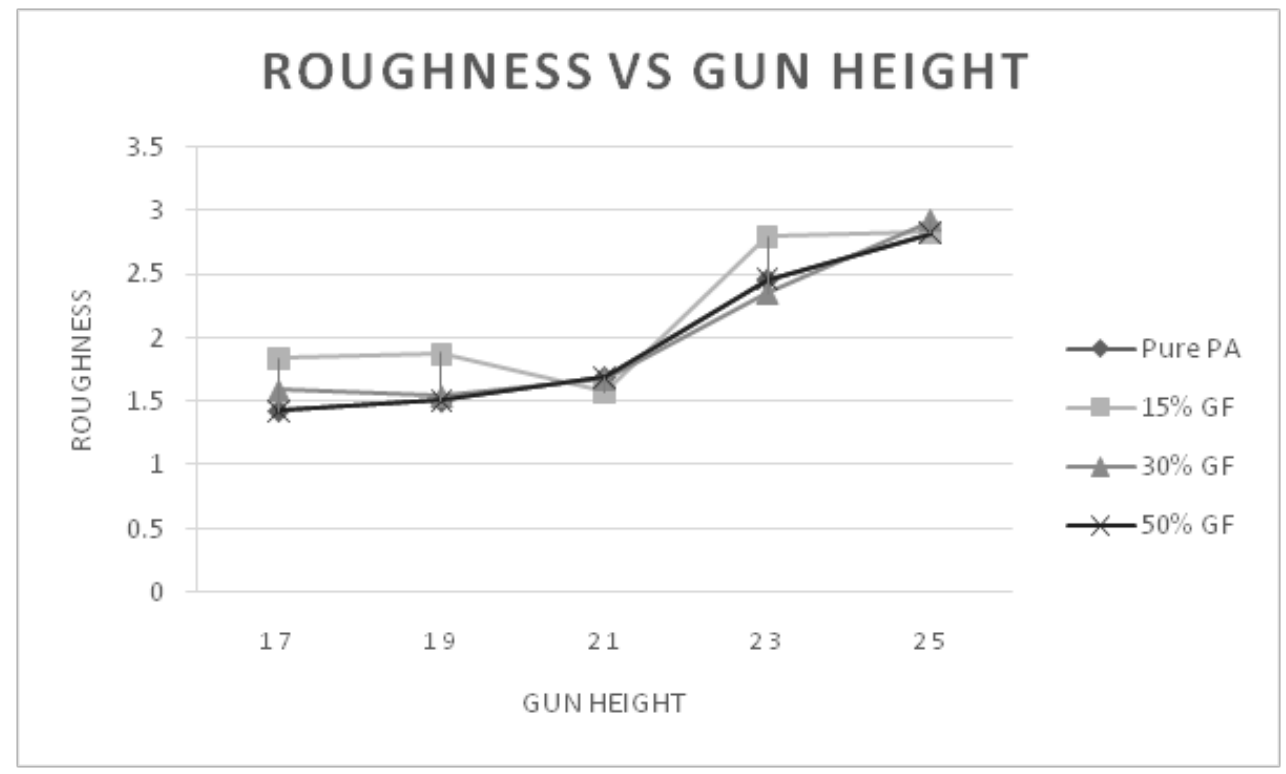

Fig. 4: Change in Surface Roughness $(\mu \mathrm{m})$ with Changing in Gun Height $(\mathrm{cm})$ 
IV.2.2. Surface Gloss

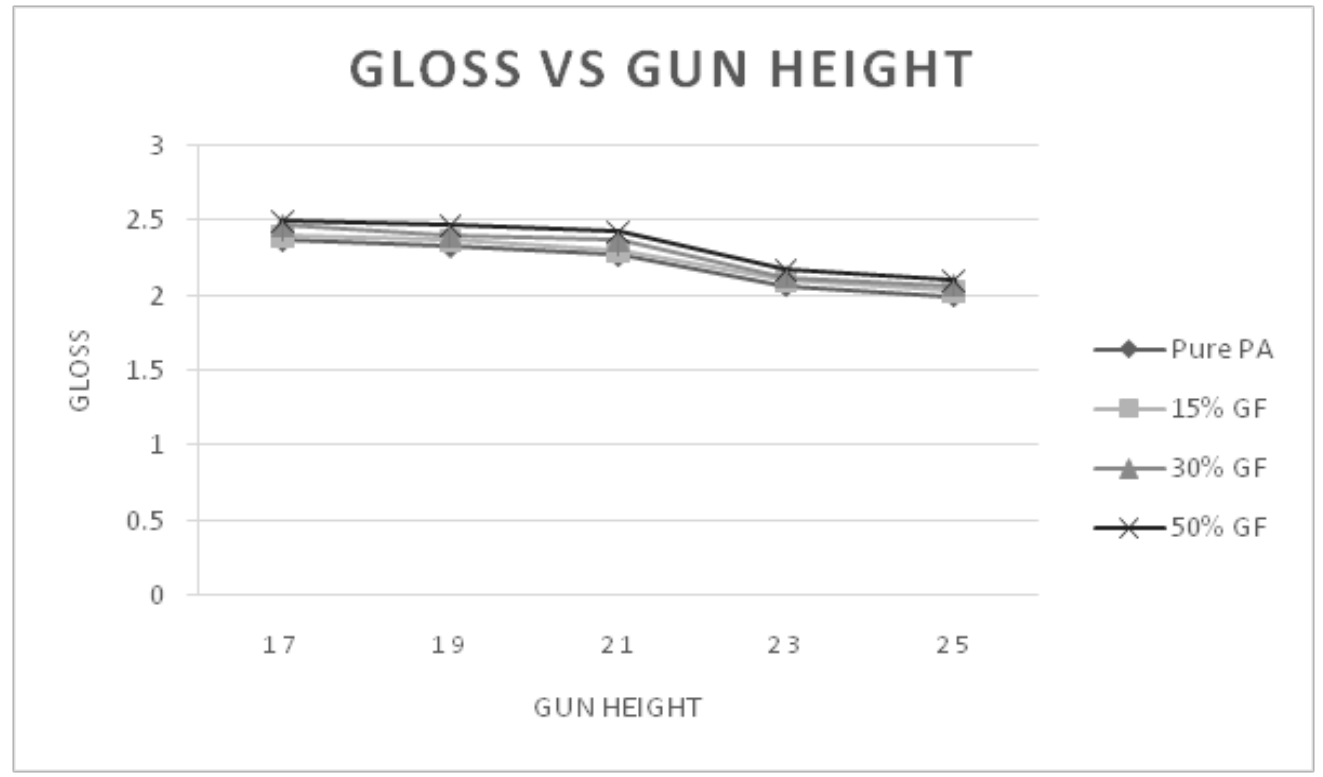

Fig. 5: Change in surface gloss with changing in gun height

Surface gloss readings of samples decreased and roughness readings increased as the gun height increased and that's because as the gun height increases the amount of material painted decreased and thus roughness increased, and gloss decreased.

IV.3. Effect of Changing Oven Drying Temperature

Time

IV.3.1. Surface Roughness

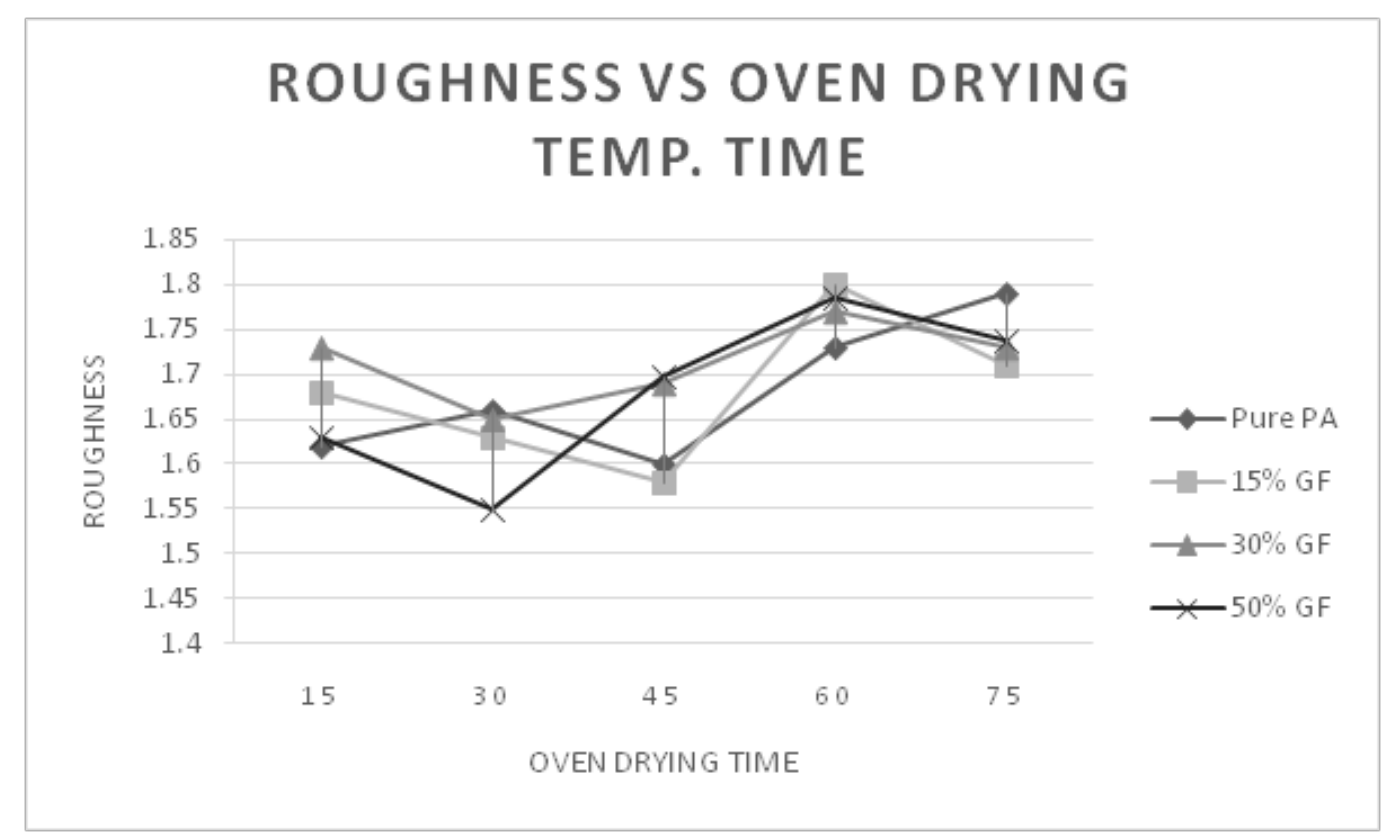

Fig. 6: Change in surface roughness with changing in oven drying temperature time 
IV.3.2. Surface Gloss

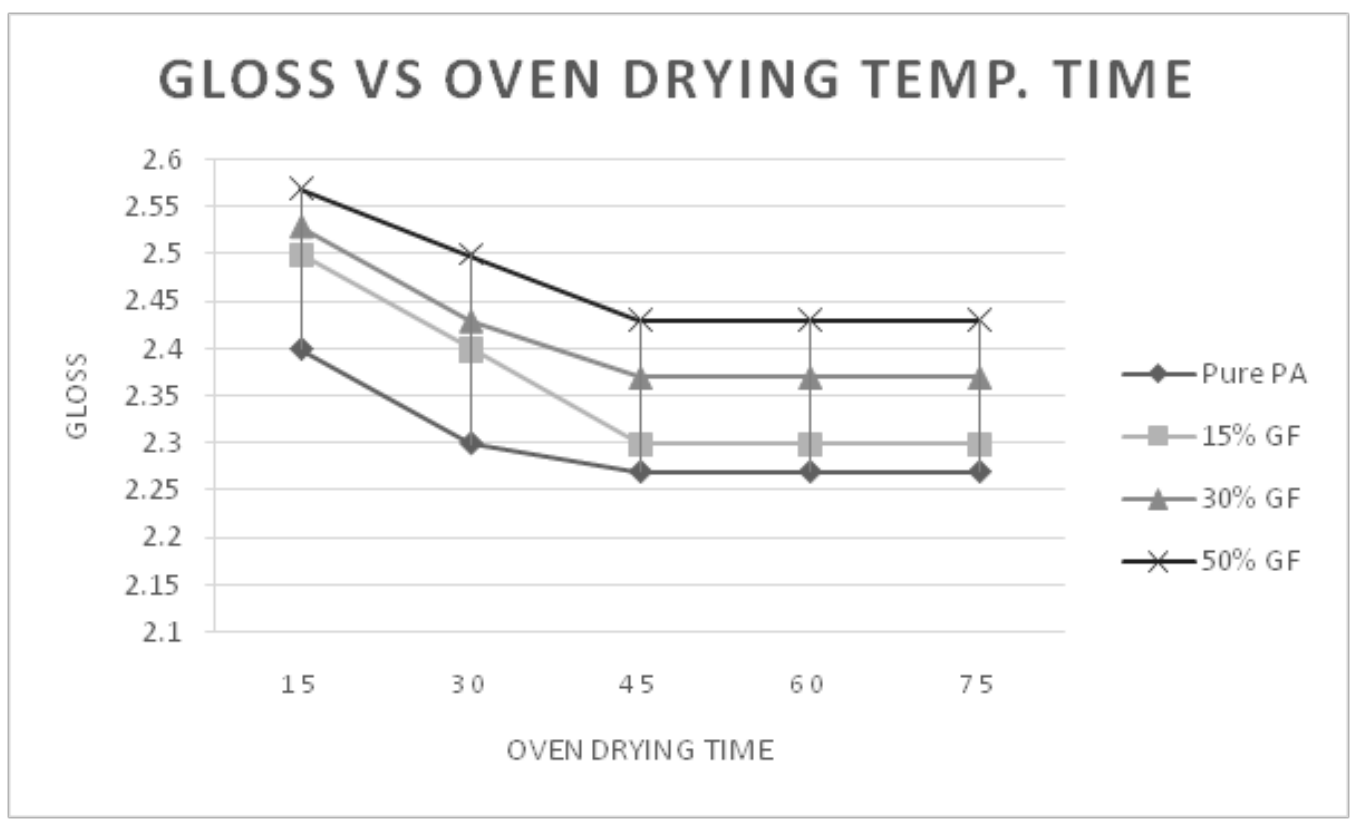

Fig. 7: Change in surface gloss with changing in oven drying temperature time

As the oven drying temp time increased roughness decreases then increases and that's because as the drying time increase, the matting agent starts to appear at surface also surface become more fired thus increasing the roughness and decreasing the gloss. And it appears that the optimum drying time is from 30 to 45 minutes.

IV.4. Effect of Changing Gun Angle

IV.4.1. Surface Roughness

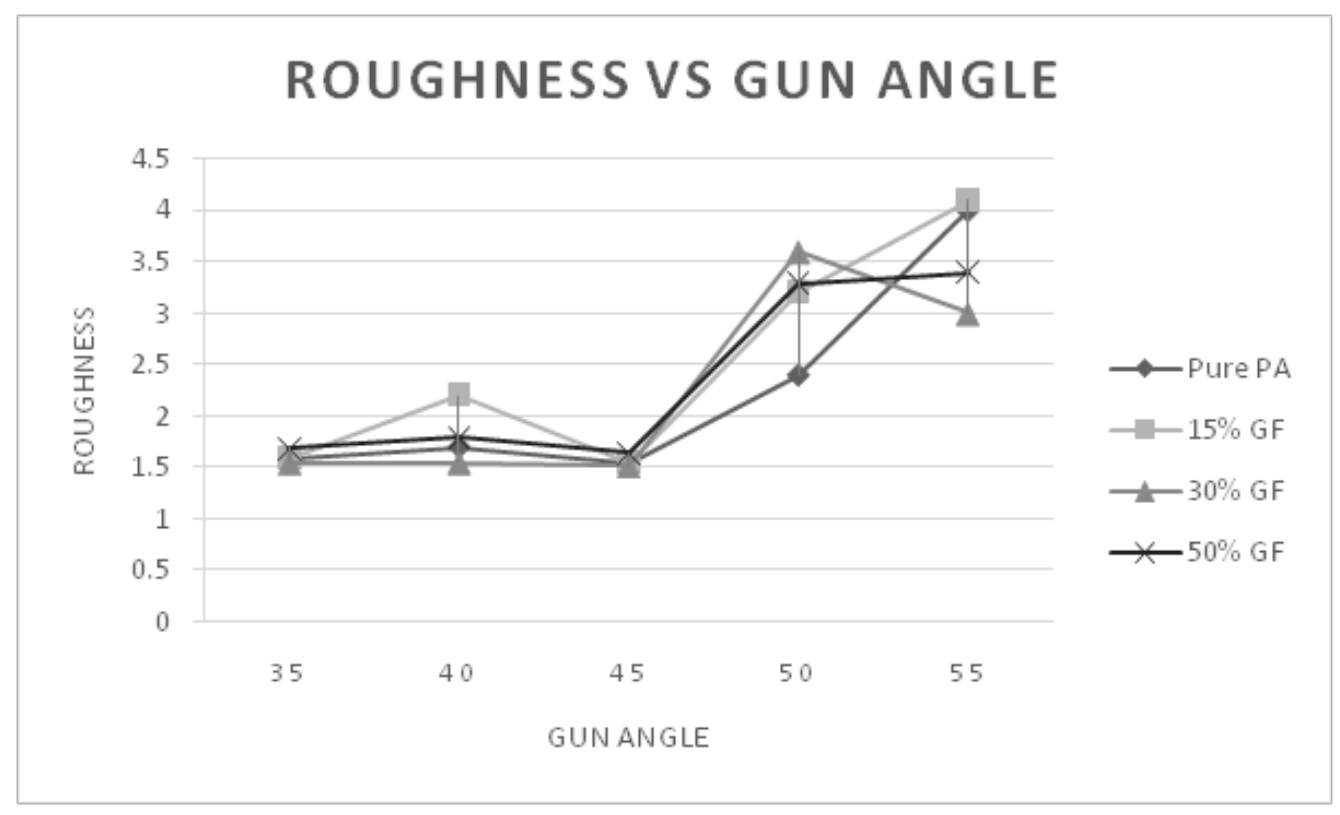

Fig. 8: Change in surface roughness and changing in gun angle 
IV.4.2. Surface Gloss

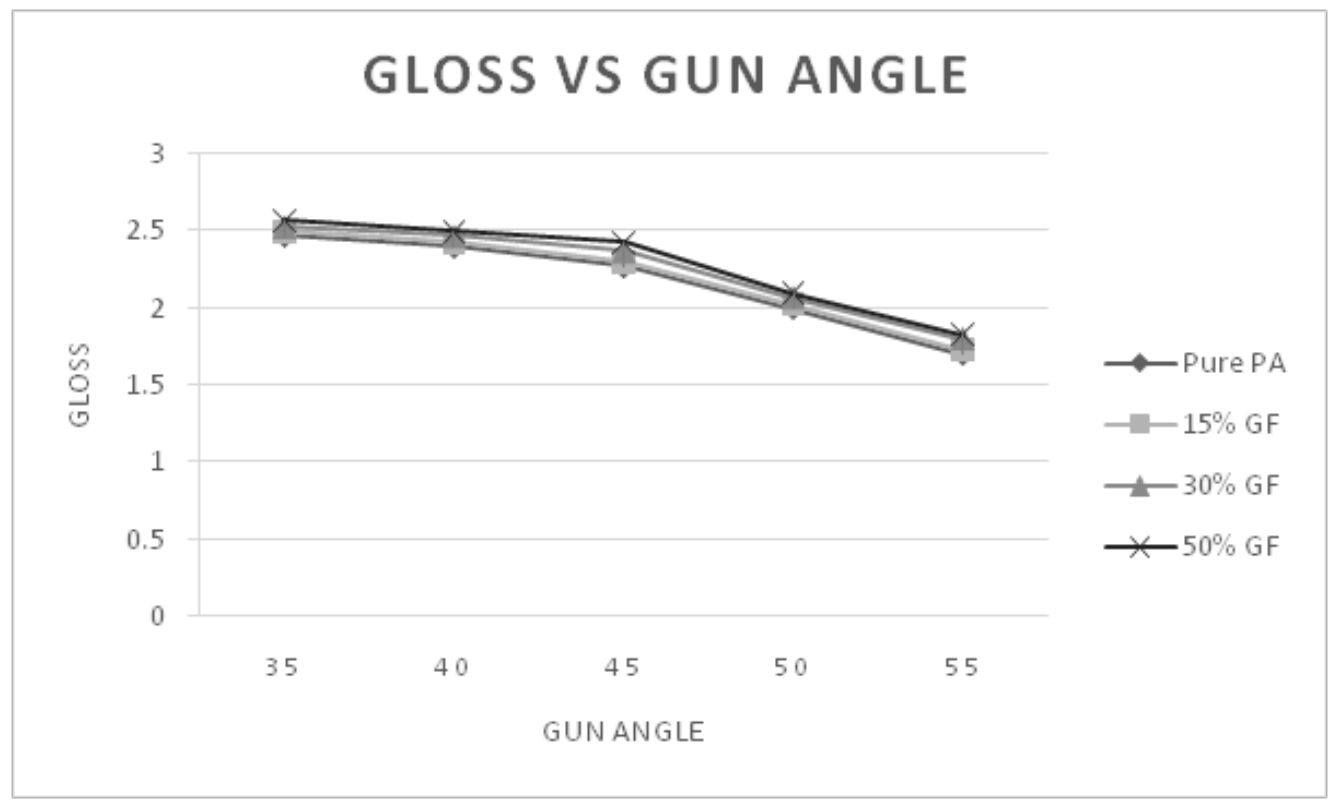

Fig. 9: Change in surface gloss with changing in gun angle

As shown in Figures 8, and 9 the change in gun angle from angle $35^{\circ}$ to $45^{\circ}$ there is small change in surface roughness (increasing) and gloss (decreasing), but for gun angle more than $45^{\circ}$ the gloss decreases and surface roughness increases but with big value. So it appears that the optimum gun angle is from $35^{\circ}$ to $45^{\circ}$.

\section{Conclusion}

The goal of the presented work is measuring the effect of variations in surface micro scale parameters on perceived gloss. The analysis of experimental work results as shown in table 1, explained that, the painting parameters greatly affects the surface topography and gloss. By changing each parameter there was a change in gloss and roughness values.Also, there's relation between gloss and roughness and somehow the roughness of surface affects its gloss since it affects the scattering of light so as the roughness of surface increases the gloss decreases. Our results showed that we can change the parameter values to get certain gloss range. Also we can conclude that the optimum oven drying time is from 30 to 45 minutes, and the optimum gun angle is from $35^{\circ}$ to $45^{\circ}$.

Table 1: Effect of changing painting process parameters on surfaces roughness and gloss

\begin{tabular}{lccccc}
\hline Parameter & $\begin{array}{c}\text { Range of change } \\
\text { in parameter }\end{array}$ & Pure PA gloss range & $15 \%$ GF gloss range & 30\% GF gloss range & $50 \%$ GF gloss range \\
\hline Oven drying time & $15-75$ min & $2.27-2.4$ & $2.3-2.5$ & $2.37-2.53$ & $2.43-2.57$ \\
Material pressure & $1-3$ & $2-2.47$ & $2-2.5$ & $2-2.5$ & $2-2.57$ \\
Drying flash time & $0.4-1.2$ & $1.9-2.5$ & $2-2.5$ & $2-2.5$ & $2-2.6$ \\
Gun angle & $35-55$ & $1.7-2.47$ & $1.7-2.5$ & $1.7-2.5$ & $2-8-2.6$ \\
Gun height & $17-23$ & $2-2.37$ & $2-2.4$ & $2-2.5$ & $2.1-2.5$ \\
\hline
\end{tabular}




\section{REFERENCES}

[1] R. alexander-katz, R. G. barrera, Surface Correlation Effects on Gloss, Journal of Polymer Science: Part B: Plymer Physics, Vol. 36, Pp1321-1334 (1998), 1998 John Wiley and Sons, Inc. CCC 0887-6266/98/081321-14

[2] Lisa M. Farrier, influence of surface roughness on the specular reflectance of low gloss coatings using bidirectional reflectance measurements, Air Force Research Laboratory, October 2006.

[3] Granzier, J. J. M., Vergne, R., and Gegenfurtner, K. R., The effects of surface gloss and roughness on color constancy for real 3-D objects, Journal of Vision, Vol. 14(2):16, Pp 1-20, 2014.

[4] Milan jaić, Tanja palija, High gloss finish: the impact of surface roughness on gloss, ZASTITA MATERIJALA, Vol.56, Pp. $457-462,2015$.
[5] Makiko Yonehara, Tsutomu Matsui, Koichiro Kihara, Hiroaki Isono, Akira Kijima and Toshio Sugibayashi, Experimental Relationships between Surface Roughness, Glossiness and Color of Chromatic Colored Metals, Materials Transactions, Vol. 45, No. 4, Pp. 1027 - 1032, 2004

[6] P. Sanmartín, B. Silva, and B. Prieto, Effect of Surface Finish on Roughness, Color, and Gloss of Ornamental Granites, Journal of Materials in Civil Engineering, Vol. 23, No. 8, Pp 1239-1248, August 2011.

[7] Lin Qi, Measuring Perceived Gloss of Rough Surfaces, Ph.D., School of Mathematical and Computer Sciences, Heriot-Watt University, July 2012.

[8] Hal F. Brinson, L. Catherine Brinson, Polymer Engineering Science and Viscoelasticity, Springer, 2nd Edition, 2018

[9] M. Wesselmann and P. Devos, "Gloss Control in Injection Molding," in First ESA form Conference, Sophia-Antipolis, France, March 1998 